Article

\title{
A Second Generation Mn-Porphyrin Dimer with a Twisted Linker as a Potential Blood Pool Agent for MRI: Tuning the Geometry and Binding with HSA
}

\author{
Hanlin Liu $1,2,+$, Weiran Cheng ${ }^{1,2, \dagger}$, Shili Dong ${ }^{2}$, David Feng $\mathrm{Xu}^{2}{ }^{2}$, Keith Tang ${ }^{1,2}$ and \\ Xiao-an Zhang 1,2,3,* \\ 1 Department of Chemistry, University of Toronto, 80 St. George Street, Toronto, ON M5S 3H6, Canada; \\ hanlin.liu@mail.utoronto.ca (H.L.); weiran.cheng@mail.utoronto.ca (W.C.); \\ keithh.tang@mail.utoronto.ca (K.T.) \\ 2 Department of Physical and Environmental Sciences, University of Toronto Scarborough, 1265 Military Trail, \\ Toronto, ON M1C 1A4, Canada; shili.dong@mail.utoronto.ca (S.D.); davidfeng.xu@mail.utoronto.ca (D.F.X.) \\ 3 Department of Biological Sciences, University of Toronto Scarborough, 1265 Military Trail, Toronto, ON M1C \\ 1A4, Canada \\ * Correspondence: xiaoan.zhang@utoronto.ca; Tel.: +1-416-287-7202 \\ + These authors contributed equally to this work.
}

Received: 24 August 2020; Accepted: 27 September 2020; Published: 29 September 2020

\begin{abstract}
Blood-pool agents (BPAs) are MRI contrast agents (CAs) characterized by their long circulation in the vascular system to provide an extended time window for high-resolution MR angiography (MRA). Prolonged vascular retention, however, impedes the excretion of BPAs. Therefore, chemical strategy to regulate the balance between retention and clearance is important to reach optimal pharmacokinetics. We recently developed $\mathrm{MnP} 2$, the first $\mathrm{Mn}(\mathrm{III})$-porphyrin (MnP) based BPA. MnP2 shows high $T_{1}$ relaxivity $\left(r_{1}\right)$ and high affinity to human serum albumin (HSA) that leads to up to 48 -h vascular retention in rats. However, upon albumin binding, the $r_{1}$ is decreased. To modulate vascular retention time and plasma $r_{1}$, a regioisomer of $\mathrm{MnP} 2, m-\mathrm{MnP} 2$, was synthesized. The free $m$-MnP2 exhibits lower $r_{1}$ than that of MnP2 at magnetic fields above $2 \mathrm{MHz}$, which agrees with their relative hydrodynamic sizes. The HSA binding of $m-\mathrm{MnP} 2$ was evaluated using UV-Vis spectroscopy and found to have tuned-down affinity in comparison with MnP2. Upon HSA binding, the protein complex of $m$-MnP2 exhibits an $r_{1}$ of $11.8 \mathrm{mM}^{-1} \mathrm{~s}^{-1}$ at $3 \mathrm{~T}$, which is higher than that of MnP2 bound to HSA. Taken together, this demonstrated the role of molecular geometry in optimizing the pharmacokinetics of albumin-targeting BPAs.
\end{abstract}

Keywords: MRI contrast agents; blood pool agent; manganese porphyrin; human serum albumin

\section{Introduction}

Developed for magnetic resonance angiography (MRA) [1], blood-pool agents (BPAs) are used to provide anatomical and functional information of the vascular system and to diagnose vascular related diseases such as atherosclerosis and hemorrhage [2]. The only FDA approved BPA is Gadofosveset (formerly MS-325), a gadolinium (Gd)-based contrast agent (GBCA). Gadofosveset is designed to bind non-covalently to HSA [3,4], the most abundant carrier protein in the blood, for prolonged blood circulation and increased relaxivity. GBCAs are, however, associated with a severe adverse effect known as nephrogenic systemic fibrosis (NSF) in patients with kidney dysfunction. The in vivo deposition of Gd ions found in NSF subjects by post-mortem analysis implies that the high thermodynamic stability of Gd complexes in vitro is compromised in vivo when renal clearance is impeded, especially for GBCAs with linear chelates [5]. More recently, cases of Gd-deposit in the brain were increasingly 
reported, even in patients with healthy kidneys [6,7]. Thus, the main concern of using Gd-based BPAs for MRA is the increased risk of toxic Gd(III) ion release and accumulation due to the long vascular retention. Moreover, due to poor sales, Gadofosveset was withdrawn from the market. Therefore, a next generation BPA with improved efficacy and safety profile is demanded to fill the gap. To avoid risk of Gd-toxicity completely, Gd-free MRI CAs with high relaxivity are desired.

We chose manganese(III) porphyrins (MnPs) to construct non-Gd BPAs because of their biocompatibility, high stability, high relaxivity especially at high magnetic fields, and versatility for structural modulation [8-12]. Unlike Gd, which is a rare earth element exogenous to human body, $\mathrm{Mn}$ is an essential micronutrient and as such is more biocompatible than Gd. Furthermore, upon metal insertion into the rigid porphyrin macrocycle, the $\mathrm{Mn}(\mathrm{III})$ complex formed is kinetically inert and thermodynamically stable against metal dissociation, thanks to the strong metal-ligand interaction. In comparison, Gd(III) complexes are kinetically labile, due to poor orbital overlap between the $f 7$ metal ion and the organic ligand. In terms of relaxivity, certain water-soluble MnPs were seen to exhibit significantly higher $T_{1}$ relaxivity $\left(r_{1}\right)$ compared to GBCAs of comparable molecular weight [8]. Finally, meso-substituted porphyrin chemistry is well known for the versatile synthetic methods established during the past few decades, allowing for feasibility and flexibility for structural modifications. An array of new MnPs have been designed and constructed for various specific purposes, including extracellular [10], intracellular [9], tumour-targeting [12], and molecular sensing [11] applications.

A dimeric $\mathrm{MnP}, \mathrm{MnP} 2$, was recently developed by our group and was found to exhibit anomalously high $r_{1}$ at clinical magnetic field strengths ranging from 1 3 T [8]. In principle, a high field is the preferred condition for MRA to improve the $\mathrm{S} / \mathrm{N}$ ratio, resolution and scan time [13]. At $3 \mathrm{~T}$, the molar $r_{1}$ of $\mathrm{MnP} 2$ in the form of the HSA complex was found to be twice that of Gadofosveset-HSA. Interestingly, however, the $r_{1}$ of $\mathrm{MnP} 2$ is slightly decreased upon HSA binding, suggesting that MnP2 may be buried in the hydrophobic protein pocket, hindering water access to the Mn(III) ion [14]. The hydrophobic biphenyl linker of MnP2 contributes to strong HSA binding, resulting in a significantly prolonged vascular circulation, relative to other MnPs, such as $\mathrm{Mn}$ (III) meso-tetra(4-sulfonato-phenyl)porphine (MnTPPS) and Gd-based CAs [14-16].

The long-circulating MnP2 opens the possibility of continuous longitudinal MRA with a single BPA injection. Some MRA applications, however, can be completed relatively quickly if further monitoring is not required. Rapid clearance can reduce in vivo exposure to exogenous CAs and therefore lower the risk of side-effects. This is crucial for GBCAs since insufficient renal clearance is known to cause NSF. Even though the MnP-based CAs are free of Gd toxicity, a chemical approach to adjust the balance between retention and clearance is valuable, as modern applications of MRA are rapidly diversifying. To accommodate the various criteria of different MRA applications, we anticipated that by tuning the binding interaction between $\mathrm{MnP}$ and HSA, the vascular retention of the $\mathrm{MnP}$ can be controlled. Since the biphenyl linker (Figure 1) of MnP2 is believed to be the major binding domain for HSA, perturbation of the biphenyl unit will change how the MnP interacts with the protein. Furthermore, modulation of the binding with HSA may avoid the water hindrance that is assumed in the MnP2-HSA complex [14] and thereby improve plasma $r_{1}$ of the MnP. In this article, a new dimeric MnP, $m-\mathrm{MnP} 2$ with a twisted biphenyl linker (Figure 1), was designed, synthesized, and characterized. 

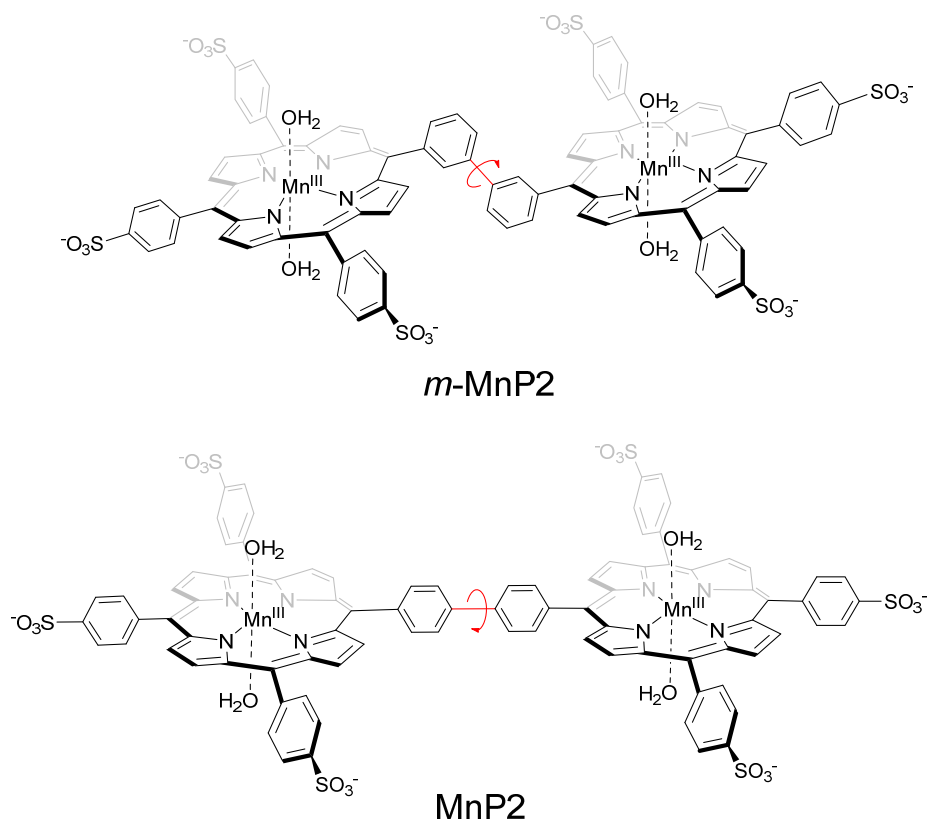

Figure 1. Chemical structure of $m-\mathrm{MnP} 2$ (top) designed with a biphenyl bridge connected at the meta-positions. MnP2 (bottom) is connected at the para- position of the biphenyl.

\section{Results and Discussion}

\subsection{Synthesis}

The synthesis of $m$-MnP2 (Scheme 1) followed a similar pathway to that of MnP2 [8]. The monomeric porphyrin building block 1 was synthesized using a mild acid catalyzed condensation reaction between aldehydes and pyrrole [17]. Dimerization of 1 via a palladium catalyzed homolytic coupling reaction produced 2 at 56\% yield [18]. Taking advantage of the low solubility of 2 , the intermediate was purified by multiple washes of $40 / 60 \mathrm{CH}_{2} \mathrm{Cl}_{2} /$ hexanes and diethyl ether with repeats of centrifugation followed by sonication until the organic solvent was colourless upon centrifugation. Purity of 2 was solely confirmed by TLC due to low solubility. Sulfonation of 2 was carried out using concentrated sulfuric acid. Because the starting material 2 is insoluble in water, the progress of the reaction could be monitored with UV-visible absorption at $422 \mathrm{~nm}$ of the aqueous aliquot, indicating the graduate formation of the polar and water-soluble product $m-\mathrm{P} 2$ in solution. Unlike the previously synthesized P2 [8], 2's reactive para-position of the biphenyl ring is open to possible sulfonation side reaction. Therefore, careful control of the reaction conditions were required. To minimize under- or over-sulfonation (Figure S8), the optimal conditions was found to be $6 \mathrm{~h}$ under $55^{\circ} \mathrm{C}$, yielding the most desired product (36\%), eluting at $5.8-7 \mathrm{~min}$ on reverse phase HPLC using an Agilent Eclipse XDB-C18 $4.6 \times 150 \mathrm{~mm}(5 \mu \mathrm{m}$ particle size) column using a gradient sequence $0-8 \mathrm{~min}$ : linear gradient from $26 \%$ to $30 \%$ acetonitrile; $8-9 \mathrm{~min}$ : linear gradient from $30 \%$ to $50 \%$ acetonitrile; $9-12 \mathrm{~min}$ : constant $50 \%$ acetonitrile at a flow rate of $0.8 \mathrm{~mL} / \mathrm{min}$. A reverse phase automated flash chromatography system was used to purify $m$-P2, characterized by ${ }^{1} \mathrm{H}-\mathrm{NMR}$ and ESI-MS (see Supporting Information). Manganese insertion in the presence of air and the organic base $\mathrm{N}, \mathrm{N}$-Diisopropylethylamine (DIPEA) yielded the final product $m$-MnP2, which was filtrated using ion exchange chromatography to remove excess $\mathrm{Mn}(\mathrm{II})$ salts. The UV-visible absorption spectrum of $m$-MnP2 (Figure S6) is similar to that of $\mathrm{MnP} 2$, with a Soret band at $468 \mathrm{~nm}$ and five characteristic peaks at 380, 402, 422, 568, and $602 \mathrm{~nm}$, which are typical features of Mn(III) porphyrins [8,19]. 


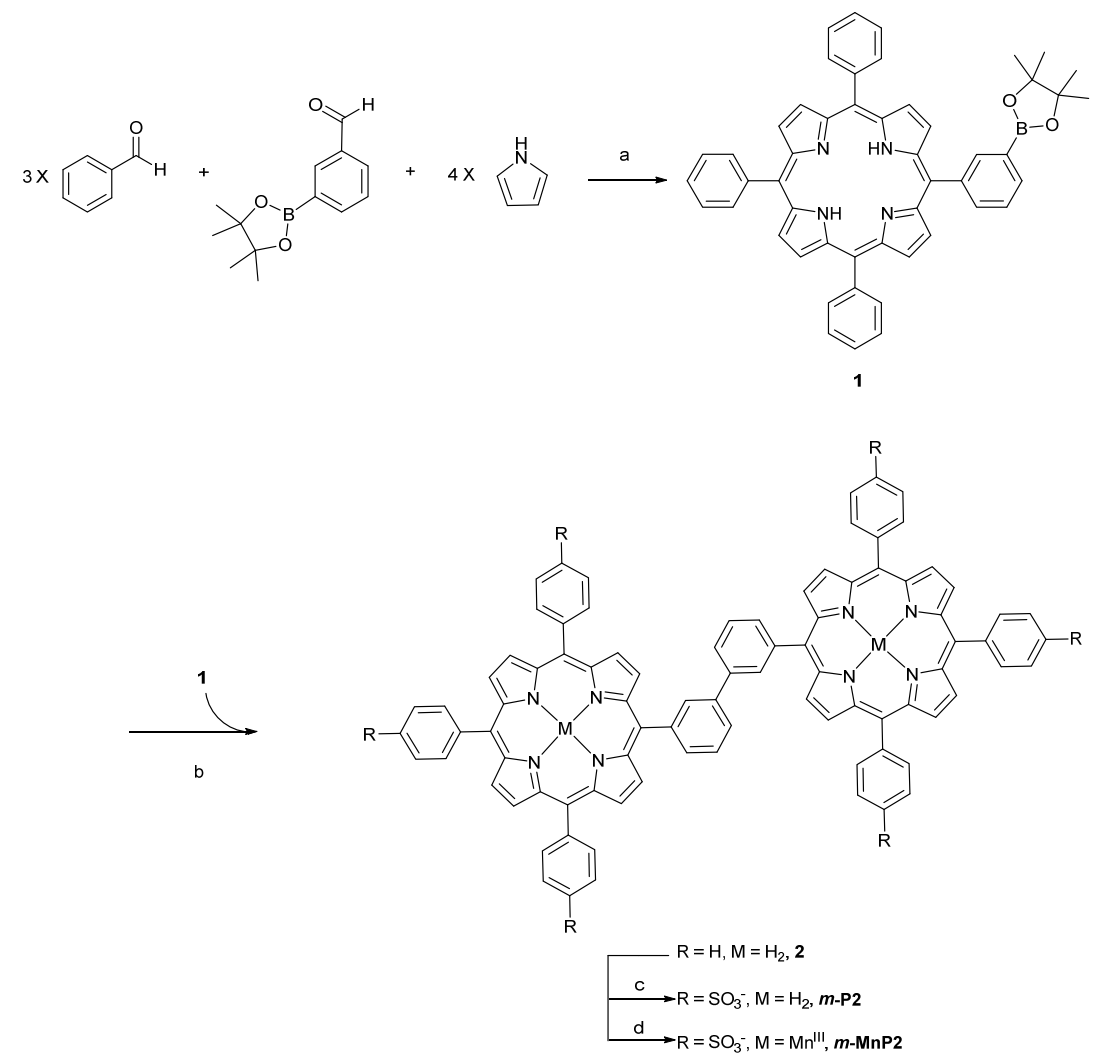

Scheme 1. (a) $\mathrm{BF}_{3} \cdot \mathrm{Et}_{2} \mathrm{O}, \mathrm{CH}_{2} \mathrm{Cl}_{2}$, DDQ, rt, $18 \%$ (b) $1, \mathrm{Pd}\left(\mathrm{PPh}_{3}\right)_{2} \mathrm{Cl}_{2}, \mathrm{TBAF}, \mathrm{H}_{2} \mathrm{O} / \mathrm{THF}, \mathrm{rt}, 56 \%$; (c) conc. $\mathrm{H}_{2} \mathrm{SO}_{4}, 55^{\circ} \mathrm{C}, 36 \%$; (d) $\mathrm{Mn}(\mathrm{OAc})_{2}$, DMF, reflux, $91 \%$.

\subsection{Relaxometry Characterization}

To investigate the field-dependent MRI relaxation enhancement efficiency of $m$-MnP2, its nuclear magnetic relaxation dispersion (NMRD) profile was acquired on a SMARTracer, coupled with an HTS-110 NMR system covering magnetic fields up to 3 T (Figure 2). The monomeric MnP building block, MnTPPS, as well as Gd-DTPA, a classic clinical GBCA, were chosen as control references for comparison.

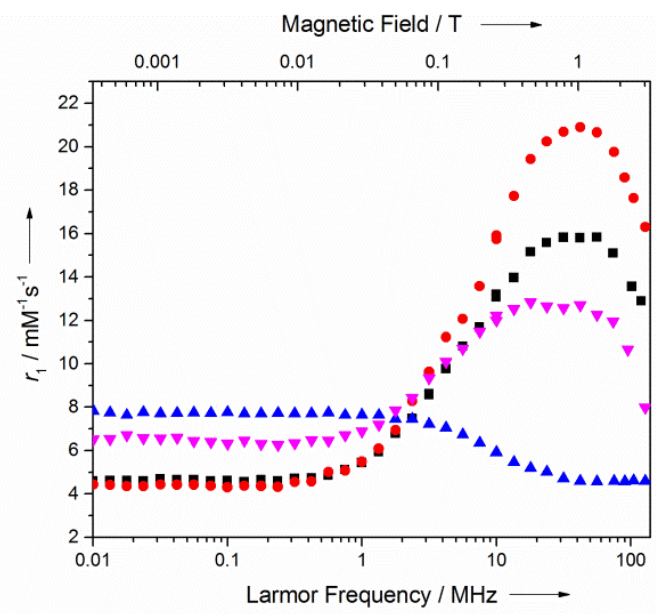

Figure 2. The nuclear magnetic relaxation dispersion (NMRD) profiles of Gd-DTPA ( $\mathbf{\Delta}), \operatorname{MnTPPS}(\boldsymbol{\nabla})$, $m-\mathrm{MnP} 2(\boldsymbol{\square})$, and MnP2() in $25 \mathrm{mM} \mathrm{pH} 7.2$ HEPES buffer from $0.23 \mathrm{mT}$ to $3 \mathrm{~T}$ at $25^{\circ} \mathrm{C}$. MnP $r_{1}$ was normalized to per Mn(III) ion. 
All the MnP CAs exhibit higher $r_{1}$ than Gd-DTPA at $1 \mathrm{~T}$, demonstrating their unique strength of high relaxivities at high clinical fields. The fully extended MnP2 attains its $r_{1}$ peak close to $1 \mathrm{~T}\left(41.8 \mathrm{mM}^{-1} \mathrm{~s}^{-1}\right.$ or $20.9 \mathrm{mM}^{-1} \mathrm{~s}^{-1}$ per $\left.\mathrm{Mn}\right)$. The intermediate relaxivity peak of $m$-MnP2 $\left(r_{1}=31.6 \mathrm{mM}^{-1} \mathrm{~s}^{-1}\right.$ or $15.8 \mathrm{mM}^{-1} \mathrm{~s}^{-1}$ per $\left.\mathrm{Mn}\right)$ at $1 \mathrm{~T}$ lying in between that of MnTPPS $\left(r_{1}=12.8 \mathrm{mM}^{-1} \mathrm{~s}^{-1}\right)$ and $\mathrm{MnP} 2$ is in agreement with its relative molecular size (Figure S7). This $r_{1}$ trend is consistent with the predicted hydrodynamic sizes, indicating that decreases in molecular tumbling rate of MnPs enhance the $r_{1}$.

As summarized in Table 1, for both MnP dimers, the high $r_{1}$ peaks are sustained at higher fields up to $3 \mathrm{~T}$ with a moderate decrease, favouring applications at high clinical magnetic fields. As a pair of constitutional isomers, the molecular weight of $m-\mathrm{MnP} 2$ and $\mathrm{MnP} 2$ are exactly the same. As shown in Figure 1, the rotation of single bond in the middle of the biphenyl unit does not cause a dramatic change on the hydrodynamic size of $\mathrm{MnP2}$, but can lead to a significant decrease to the hydrodynamic size of $m$-MnP2, as illustrated by computational molecular modeling (Figure S7). Our results demonstrated that the slight change in $\mathrm{MnP}$ connection at the biphenyl bridge resulted in a significant impact on molecular geometry and thus on the $r_{1}$.

Table 1. $r_{1}$ of free $\mathrm{MnP} 2$ and $m-\mathrm{MnP} 2$ at clinical magnetic fields normalized per $\mathrm{Mn}$, measured in 25 $\mathrm{mM} \mathrm{pH} 7.2 \mathrm{HEPES}$ at $25^{\circ} \mathrm{C}$.

\begin{tabular}{ccc}
\hline & $\boldsymbol{r}_{\mathbf{1}}$ at $\mathbf{1 . 6} \mathbf{\mathbf { T }}\left(\mathbf{m M}^{\mathbf{- 1}} \mathbf{s}^{\mathbf{- 1}}\right)$ & $\boldsymbol{r}_{\mathbf{1}}$ at $\mathbf{3} \mathbf{\mathbf { T }}\left(\mathbf{m M}^{\mathbf{- 1}} \mathbf{s}^{\mathbf{- 1}}\right)$ \\
\hline $\mathrm{MnP2}$ & 20.2 & 14.7 \\
$m-\mathrm{MnP2}$ & 15.4 & 12.9 \\
\hline
\end{tabular}

\subsection{Binding Affinity with $H S A$}

The non-covalent binding of $m-\mathrm{MnP} 2$ with HSA is crucial to understanding its potential as a BPA. Thus, a UV-visible spectroscopy titration experiment was performed in order to monitor the protein binding and to quantify the dissociation constant $K_{\mathrm{d}}$. Upon titration of HSA into $m-\mathrm{MnP} 2$, a $2 \mathrm{~nm}$ redshift at the Soret band $(468 \mathrm{~nm})$ was observed (Figure 3a). Through fitting the absorbance change at $470 \mathrm{~nm}$ over the concentration of HSA, a relatively weak $K_{\mathrm{d}}$ of $16.5 \pm 1.5 \mu \mathrm{M}$ was obtained (Figure $3 \mathrm{~b}$ ). In comparison, $\mathrm{MnP} 2$ affinity to HSA has a $K_{\mathrm{d}}=0.55 \pm 0.26 \mu \mathrm{M}$. To further confirm the affinity of $m$-MnP2 towards HSA, a circular dichroism (CD) study was performed. If the meta analogue of MnP2 is able to bind specifically and tightly to the same binding pocket as $\mathrm{MnP} 2$, then its induced chirality would produce a strong ellipicity signal. Unlike the strong ellipticity induced by the MnP2 and HSA complex [14], the $m$-MnP2 and HSA complex yields a weak signal at $472 \mathrm{~nm}$ (Figure 4), preventing further quantitative study on protein affinity. The low CD signal of the $m-\mathrm{MnP} 2-\mathrm{HSA}$ complex further implied a less specific and weak affinity of $m-\mathrm{MnP} 2$ to HSA.

\subsection{Relaxometry Studies with HSA}

We next studied how binding with HSA influences the relaxivity of $m$-MnP2. The NMRD profile for $m-\mathrm{MnP} 2$ in the presence of 1 equivalence of HSA was obtained and compared with that of free $m$-MnP2. As shown in Figure 5a, the $r_{1}$ values of $m-\mathrm{MnP} 2$ in general decreases upon HSA binding, but the magnitude of the change is field-dependent, mainly impacting the low fields. The $r_{1}$ decrease $\left(\Delta r_{1}\right)$ caused by HSA binding is more significant between 0.01 to $0.3 \mathrm{MHz}$, where the $r_{1}$ is relatively constant (4.6 $\mathrm{mM}^{-1} \mathrm{~s}^{-1}$ for free $m-\mathrm{MnP} 2$, and $3.1 \mathrm{mM}^{-1} \mathrm{~s}^{-1}$ for $m-\mathrm{MnP} 2-\mathrm{HSA}$ complex). As the field increases, the $r_{1}$ difference becomes smaller. In contrast, at fields higher than $10 \mathrm{MHz}$, the $r_{1}$ of the free and HSA bound $m-\mathrm{MnP} 2$ converge at $1 \mathrm{~T}\left(\sim 15.8 \mathrm{mM}^{-1} \mathrm{~s}^{-1}\right)$. This change in $r_{1}$ upon HSA binding is different from the NMRD profiles of MnP2, which shows a larger drop in relaxivity $\left(\Delta r_{1}\right)$ at both low and high magnetic fields upon HSA binding (Figure $5 b$ ). 

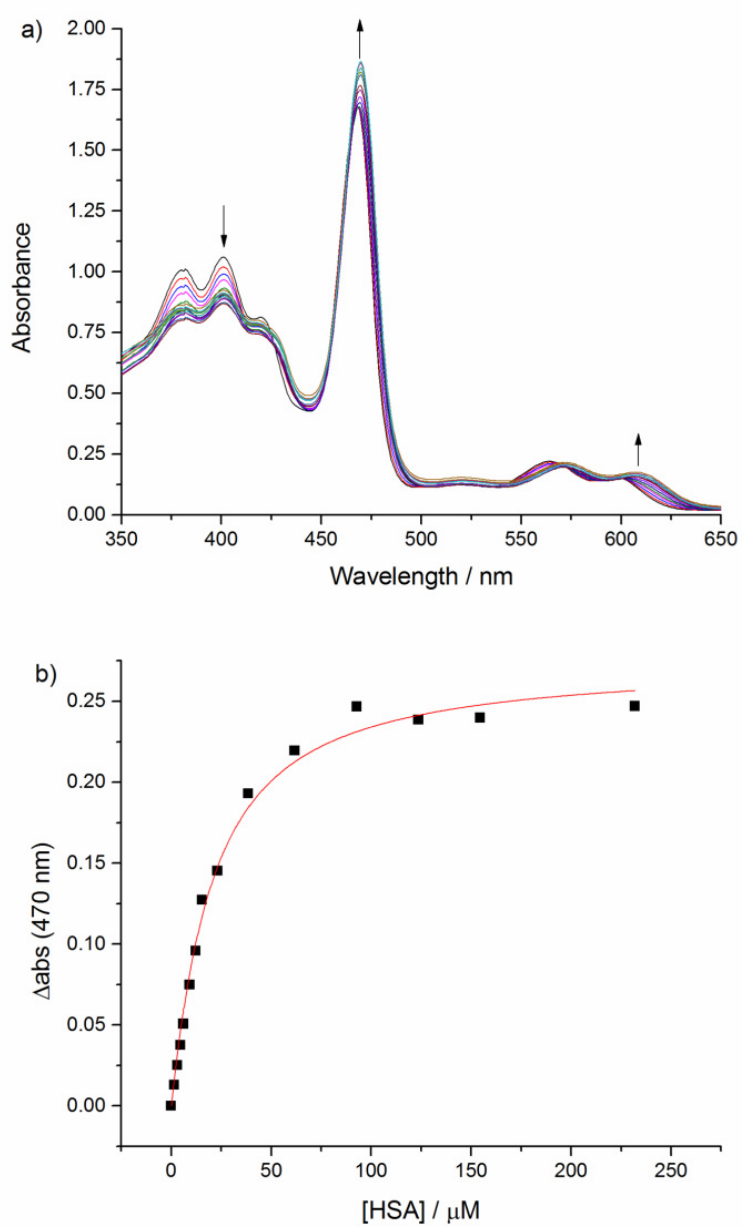

Figure 3. (a) UV absorbance spectra of $7.7 \mu \mathrm{M} m-\mathrm{MnP} 2$ titrated against $0-15$ eq. of human serum albumin (has) in $25 \mathrm{mM} \mathrm{pH} 7.2$ HEPES buffer at $25^{\circ} \mathrm{C}$. (b) The change in UV-Vis absorbance at $470 \mathrm{~nm}$ was plotted and fitted using OriginLab ${ }^{\circledR} 9.0$ to obtain a dissociation constant $K_{\mathrm{d}}$ of $16.5 \pm 1.5 \mu \mathrm{M}$ (see supporting information for details).

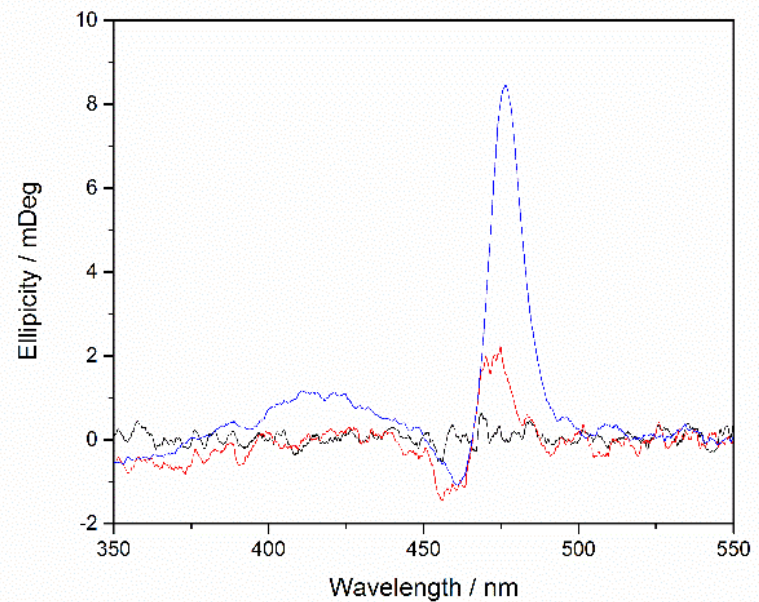

Figure 4. Circular dichroism (CD) spectra of 25 mM HEPES buffer (black), m-MnP2 with 1 eq. of HSA (red), and MnP2 with 1 eq. HSA (blue). Concentrations of MnPs are normalized to $3 \mu \mathrm{M}$. 

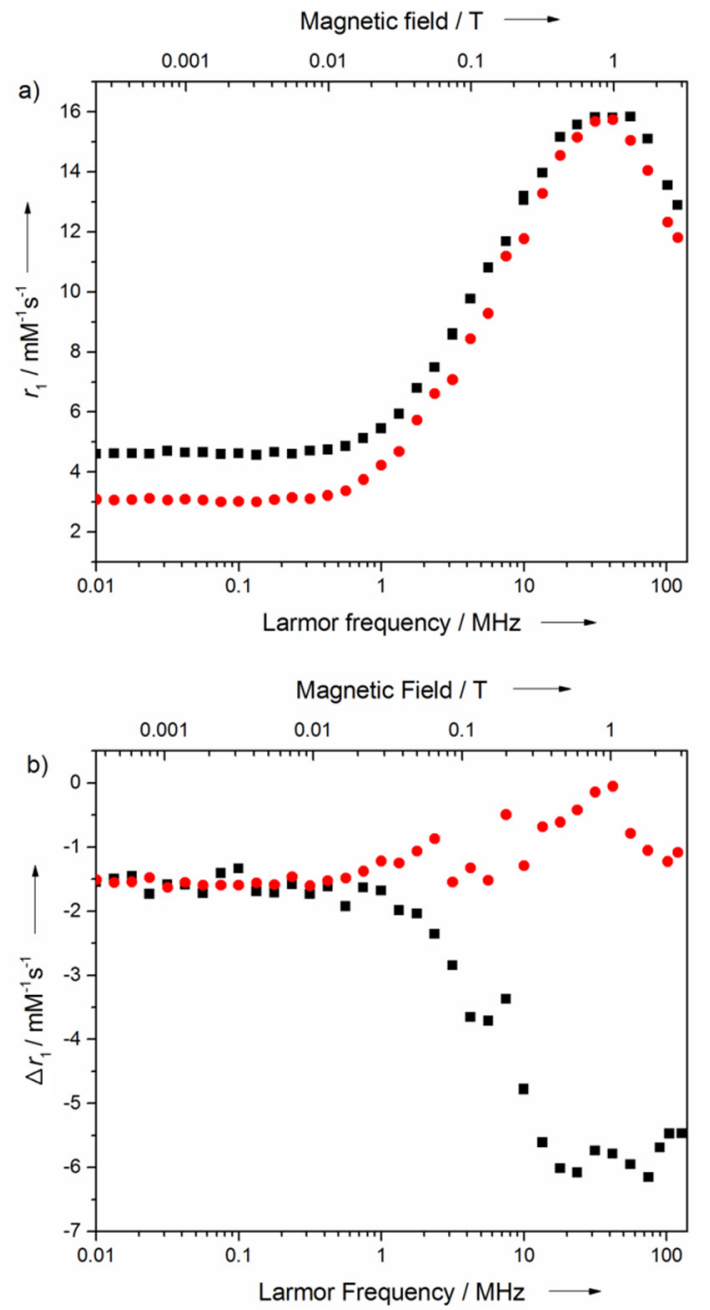

Figure 5. (a) NMRD profiles of free $m-\mathrm{MnP} 2(\mathbf{a})$ and $m-\mathrm{MnP} 2$ with HSA (-) in $24 \mathrm{mM}$ pH 7.2 HEPES buffer measured at $25^{\circ} \mathrm{C}$ from $0.01-128 \mathrm{MHz}$. (b) The change in $r_{1}$ of $m$-MnP2 (O) and MnP2 (匹) upon binding with HSA.

Although MnP2 has higher $r_{1}$ at high clinical fields compared to $m-\mathrm{MnP} 2$, the compromised $r_{1}$ $\left(\Delta r_{1}\right)$ for MnP2 upon binding with HSA is much greater than that for $m$-MnP2 (Figure $5 \mathrm{~b}$ ). As a result, both agents are expected (and implied) to have very similar in vivo contrast enhancement efficacy, assuming similar pharmacokinetics. The similar NMRD profiles shown in Figure 6 suggest that, at low field, the relatively fast electron relaxation of MnPs makes electron relaxation time $\tau_{\mathrm{e}}$ the dominant correlation time. At the high field, where electron relaxation slows down, the tumbling rate $\tau_{\mathrm{R}}$ becomes the dominant factor. However, because the NMRD profile is governed by many interplayed factors, other possibilities that lead to this coincidence of similar NMRD cannot be excluded. 


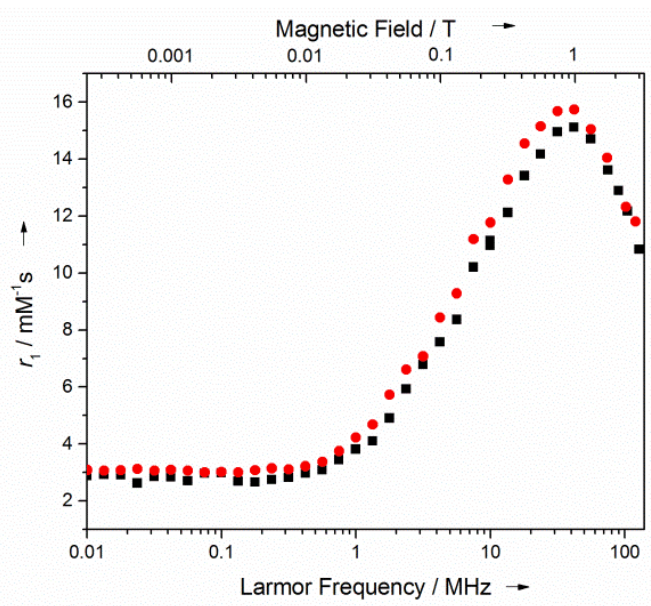

Figure 6. NMRD profiles of MnP2-HSA ( $(\bullet)$ and $m$-MnP2-HSA ( $\square)$ in pH $7.225 \mathrm{mM}$ HEPES at $25{ }^{\circ} \mathrm{C}$, measured from $0.01-128 \mathrm{MHz}$.

\section{Materials and Methods}

All reagents and solvents were of commercial reagent grade and were used without further purification except where noted. Pyrrole, benzaldehyde, and $\mathrm{BF}_{3} \cdot \mathrm{Et}_{2} \mathrm{O}$ were obtained from Sigma-Aldrich. 3-boropinacolatobenzaldehyde was purchased from Boron Molecular. DDQ and $\mathrm{Pd}\left(\mathrm{PPh}_{3}\right) \mathrm{Cl}_{2}$ were obtained from AK Scientific, Inc. (Union City, CA, USA) TBAF was purchased from Alfa Aesar. HEPES buffer ( $25 \mathrm{mM}$, pH 7.2) fixed at the ionic strength of $0.1 \mathrm{M}$ using $\mathrm{NaCl}$ was used for all measurements. HSA was purchased from Sigma Chemical Co. (St. Louis, MO., USA) and its molecular weight was assumed to be $66,478 \mathrm{Da}$ as specified. All other reagents and solvents were purchased from Caledon Laboratories, Ltd. (Georgetown, ON, Canada) TLC was performed using TLC silica gel $60 \mathrm{~F}_{254}$ plates from Merck KGaA. Column Chromatography was set up using Silica Gel 60, 250-400 microns from Desican Inc. (Scarborough, ON, Canada) Cation ion exchange was performed using an Amberlite ${ }^{\circledR}$ IR120, H resin. Dialysis was performed with Sigma Aldrich Pur-A-Lyzer ${ }^{\mathrm{TM}}$ Mega 3500 MWCO. All the spectroscopy data for structural characterizations were obtained using the research facilities at University of Toronto Scarborough campus (TRACES center) or at St. George campus (Chemistry Department). NMR spectra were recorded on Bruker-500 MHz or Varian Unity $500 \mathrm{MHz}$ spectrometer. UV-Visible absorption spectra were recorded on an Agilent 8453 Spectroscopy System in a $1 \mathrm{~cm}$ path length cuvette at a scan rate of $4800 \mathrm{~nm} / \mathrm{min}$ and data points were taken every $1 \mathrm{~nm}$. Mass spectra were obtained from an ABI/Sciex Qstar mass spectrometer (ESI). CD spectra were obtained using Jasco J-815 Circular Dichroism Spectrophotometer. The CD spectrum was recorded in a $1 \mathrm{~cm}$ path length cuvette at a scan rate of $100 \mathrm{~nm} / \mathrm{min}$ and data points were taken every $0.1 \mathrm{~nm}$.

\section{Synthesis}

5-(3-boropinaocolatophenyl)-10,15,20-triphenylporphyrin (1): The reaction was carried out in the dark under room temperature. $520 \mathrm{~mL} \mathrm{DCM}, 1.3 \mathrm{~g} \mathrm{NaCl}(22.2 \mathrm{mmol})$ and $2.68 \mathrm{~g}$ 3-boropinacolatobenzaldehyde $(11.48 \mathrm{mmol})$ were stirred in a $1 \mathrm{~L}$ round bottom flask for $20 \mathrm{~min}$ under argon atmosphere. $3.2 \mathrm{~mL}$ pyrrole $(45.98 \mathrm{mmol})$ and $3.52 \mathrm{~mL}$ benzaldehyde $(34.83 \mathrm{mmol})$ were added and stirred for $10 \mathrm{more} \mathrm{min} .0 .52 \mathrm{~mL} \mathrm{BF}_{3} \cdot \mathrm{Et}_{2} \mathrm{O}(4.30 \mathrm{mmol})$ was then added dropwise. After $1 \mathrm{~h}$ of additional stirring, $7.84 \mathrm{~g}$ DDQ $(36.12 \mathrm{mmol})$ was added to the mixture followed by $2 \mathrm{~h}$ of stirring. The dark green crude solution was concentrated by rotary evaporation followed by filtration using a double-layer silica/alumina column, washed with DCM. The filtered solution was concentrated and purified by column chromatography on silica gel with elution solvent 7:3 DCM/hexanes. $380.0 \mathrm{mg}$ $(18 \%)$ of 1 was isolated as dark purple solid. ESI-MS (positive mode, DCM/Methanol, Figure S3) found $m / z=741.4\left([\mathrm{M}+\mathrm{H}]^{+}\right)$, calculated for $\mathrm{C}_{50} \mathrm{H}_{42} \mathrm{BN}_{4} \mathrm{O}_{2}{ }^{+}(\mathrm{m} / \mathrm{z}=741.34) .{ }^{1} \mathrm{H}-\mathrm{NMR}\left(500 \mathrm{MHz}, \mathrm{CDCl}_{3}\right.$, 
Figure S1): $\delta(\mathrm{ppm})-2.79(2 \mathrm{H}, \mathrm{s}, \mathrm{NH}), 1.39(12 \mathrm{H}, \mathrm{s}$, methyl), $7.76(10 \mathrm{H}, \mathrm{m}$, phenyl), $8.22(7 \mathrm{H}, \mathrm{m}$, phenyl), $8.29(1 \mathrm{H}, \mathrm{d}, J=8 \mathrm{~Hz}$, sub Ph-p), $8.65(1 \mathrm{H}$, s, sub Ph-o'), $8.84(8 \mathrm{H}, \mathrm{m}$, por- $\beta)$.

3,3'-bis(5,10,15-triphenylporphyrin-20-yl)biphenyl (2): $22.2 \mathrm{mg}$ of 1 ( $0.03 \mathrm{mmol})$ was added along with $2.2 \mathrm{mg} \mathrm{Pd}\left(\mathrm{PPh}_{3}\right)_{2} \mathrm{Cl}_{2}(0.003 \mathrm{mmol})$ and $10.9 \mathrm{mg}$ TBAF $(0.035 \mathrm{mmol})$ in a reaction flask. $2.68 \mathrm{~mL}$ of a 1:4 mixture of $\mathrm{dH}_{2} \mathrm{O}$ :THF was added as solvent. The reaction mixture was stirred in room temperature while opened to air. Reaction progression was monitored using TLC (1:1 DCM/hexanes). After $3 \mathrm{~h}$ of stirring, the reaction was stopped by extraction with $\mathrm{DCM}$, in which the product was seen in the organic layer as a suspension instead of a solution. The organic layer was dried over $\mathrm{Na}_{2} \mathrm{SO}_{4}$ and concentrated via rotary evaporation. Repeated centrifugation $\left(5000 \times g, 10 \mathrm{~min}\right.$ at $25^{\circ} \mathrm{C}$ ) and resuspension of the pellet using 1:1 DCM/hexanes followed by the same procedure using diethyl ether was used to purify 2. The product was shown to be pure once the organic solvents were clear upon centrifugation. 2 was collected as a purple powder $(10.3 \mathrm{mg}, 56 \%)$. TLC was used to determine product purity $\left(R_{\mathrm{f}}=0,1: 1\right.$ DCM/hexanes).

3,3'-bis(5,10,15-tris(4-sulfonatophenyl)porphin-20-yl)biphenyl ( $m$-P2): $5 \mathrm{mg}$ of 2 (0.0041 mmol) was dissolved in $0.7 \mathrm{~mL}$ of $18 \mathrm{M}$ concentrated sulphuric acid. The solution was stirred at $55{ }^{\circ} \mathrm{C}$ for $5 \mathrm{~h}$ and quenched by neutralization with $0.1 \mathrm{M} \mathrm{NaOH}$. The crude solution was dialyzed with a 3500 MWCO membrane to remove excess salt and purified by automated flash chromatography on a $15.5 \mathrm{~g} \mathrm{C} 18$ Redisep ${ }^{\circledR} \mathrm{R}_{\mathrm{f}}$ GOLD column using acetonitrile and $10 \mathrm{mM} \mathrm{NH}_{4} \mathrm{OAc}$ as the mobile phase, using a gradient sequence $0-3 \mathrm{CV}$ : constant $25 \%$ acetonitrile; $3-12 \mathrm{CV}$ : linear gradient from $25 \%$ to $50 \%$ acetonitrile; $12-16$ CV: $50 \%$ to $100 \%$ acetonitrile at a flow rate of $35 \mathrm{~mL} / \mathrm{min}$. Purified product above $90 \%$ purity was collected and dried by lyophilisation. $2.6 \mathrm{mg}$ of dark red solid (36\%) of $m$-P2 was collected. Negative mode ESI-MS $\left(\mathrm{H}_{2} \mathrm{O}\right.$, Figure 44$)$ found $m / z=283.6\left([\mathrm{M}]^{6-}\right), 340.4\left([\mathrm{MH}]^{5-}\right), 425.8\left(\left[\mathrm{MH}_{2}\right]^{4-}\right)$, calculated for $\mathrm{C}_{88} \mathrm{H}_{48} \mathrm{~N}_{8} \mathrm{O}_{18} \mathrm{~S}_{6}{ }^{6-}(\mathrm{m} / \mathrm{z}=283.4), \mathrm{C}_{88} \mathrm{H}_{49} \mathrm{~N}_{8} \mathrm{O}_{18} \mathrm{~S}_{6}{ }^{5-}{ }^{-}(\mathrm{m} / \mathrm{z}=340.3), \mathrm{C}_{88} \mathrm{H}_{50} \mathrm{~N}_{8} \mathrm{O}_{18} \mathrm{~S}_{6}{ }^{4-}{ }^{-} \mathrm{m} / \mathrm{z}$ $=425.6) .{ }^{1} \mathrm{H}-\mathrm{NMR}\left(500 \mathrm{MHz}, \mathrm{DMSO}-d_{6}\right.$, Figure S2): $\delta(\mathrm{ppm})-2.90(4 \mathrm{H}, \mathrm{s}, \mathrm{NH}), 7.94(2 \mathrm{H}, \mathrm{t}, J=8 \mathrm{~Hz}$, bridge Ph- $m), 8.05(12 \mathrm{H}, \mathrm{m}, \mathrm{Ph}-m), 8.18(12 \mathrm{H}, \mathrm{m}, \mathrm{Ph}-0), 8.26(2 \mathrm{H}, \mathrm{d}, J=7 \mathrm{~Hz}$, bridge Ph- $p), 8.43(2 \mathrm{H}, \mathrm{d}, J$ $=8 \mathrm{~Hz}$, bridge Ph-o $), 8.78\left(2 \mathrm{H}, \mathrm{s}\right.$, bridge Ph- $\left.o^{\prime}\right), 8.85(\mathrm{~m}, 12 \mathrm{H}$, por $-\beta), 8.99(4 \mathrm{H}, \mathrm{d}, J=8 \mathrm{~Hz}$, por $-\beta)$. The extinction coefficient of $m-\mathrm{P} 2$ is $480000 \mathrm{M}^{-1} \mathrm{~cm}^{-1}$ at $422 \mathrm{~nm}$, obtained from UV-Visible measurements in $25 \mathrm{mM}$ pH 7.2 HEPES buffer based on dry mass.

3,3'-bis-Mn(III)5,10,15-tris(4-sulfonatophenyl)porphin-20-yl)biphenyl (m-MnP2): 5.0 mg m-P2 $(0.0041 \mathrm{mmol}), 11.3 \mathrm{mg} \mathrm{Mn}(\mathrm{OAc})_{2}(0.065 \mathrm{mmol})$ and $6 \mu \mathrm{L}$ DIPEA $(0.034 \mathrm{mmol})$ were stirred in $0.8 \mathrm{~mL}$ DMF for $4 \mathrm{~h}$ under reflux and monitored via UV-Visible spectroscopy. The crude was filtered to remove excess Mn(II) salts by a silica column using pure DMF as the eluent followed by dialysis using a 3500 MWCO membrane. To remove the remaining trace Mn(II) ions, an Amberlite IR120 cation exchange column (sodium form) was used to yield $7.12 \mathrm{mg}(91 \%)$ dark green powder. ESI-MS of $m-\mathrm{MnP} 2$ (negative mode, $\mathrm{H}_{2} \mathrm{O}$, Figure S5) found $m / z=451.80\left([\mathrm{M}]^{4-}\right.$ ), calculated for $\mathrm{C}_{88} \mathrm{H}_{48} \mathrm{~N}_{8} \mathrm{O}_{18} \mathrm{~S}_{6} \mathrm{Mn}_{2}{ }^{4-}(\mathrm{m} / \mathrm{z}$ $=451.5)$. The extinction coefficient of $m-\mathrm{MnP} 2$ is $212000 \mathrm{M}^{-1} \mathrm{~cm}^{-1}$ at $468 \mathrm{~nm}$, obtained from FAAS and UV-Visible measurements in $25 \mathrm{mM} \mathrm{pH} \mathrm{7.2} \mathrm{HEPES} \mathrm{buffer.}$

\section{Conclusions}

An intermediate size MnP dimer, $m$-MnP2, was designed with a twisted biphenyl linker for the investigation of its field dependent relaxivities and interaction with HSA. The molar $r_{1}$ of $m$-MnP2 peaked at $1 \mathrm{~T}\left(31.6 \mathrm{mM}^{-1} \mathrm{~s}^{-1}\right)$ and extended to higher fields up to $\sim 3 \mathrm{~T}(120 \mathrm{MHz})$ with moderate decrease $\left(25.8 \mathrm{mM}^{-1} \mathrm{~s}^{-1}\right)$, favouring high $r_{1}$ at high magnetic fields. Relative to MnTPPS and MnP2, the intermediate size of $m-\mathrm{MnP} 2$, determined by geometric flexibility, is well correlated to their respective relaxivities at the $1 \mathrm{~T}$ region. HSA titration studies monitored by UV-visible and CD spectra indicated $m$-MnP2 formed a non-covalent HSA complex, with the interaction tuned down to be less strong in contrast to $\mathrm{MnP2}$, suggesting the modification on biphenyl bridge indeed impacts the interaction with HSA. The $m$-MnP2-HSA complex exhibited weaker binding in comparison to $\mathrm{MnP} 2$ but the $r_{1}$ of both HSA complexes are comparable, especially at magnetic fields above $1 \mathrm{~T}$, thus exhibiting higher sensitivities than the regular Gd agents for high field applications. Therefore, the 
$m$-MnP2-HSA complex is expected to serve as a high relaxivity BPA with potential shorter vascular retention time and possible partial renal clearance, which will be verified by in vivo studies in the near future. The molecular principle demonstrated in this work will guide the design of future modulations of next generation BPA based on porphyrins.

Supplementary Materials: Supplementary information is available online at http://www.mdpi.com/1424-8247/13/ 10/282/s1. Figure S1. ${ }^{1} \mathrm{H}-\mathrm{NMR}$ of 1; Figure S2. ${ }^{1} \mathrm{H}-\mathrm{NMR}$ of $m$-P2; Figure S3. Mass spectrum of 1; Figure S4. Mass spectrum of $m$-P2; Figure S5. Mass spectrum of $m$-MnP2; Figure S6. UV-Visible spectra of $m$-P2 and $m$-MnP2; Figure S7 Molecular dynamics calculations for both MnP2 dimers; Figure S8 Mass spectrum of oversulfonated $m-\mathrm{P} 2$;

Author Contributions: Conceptualization, X.-a.Z.; methodology, W.C., H.L., S.D., D.F.X., and K.T.; validation, H.L., W.C. and X.-a.Z.; data analysis, W.C. and H.L.; writing-original draft preparation, H.L., W.C., and X.-a.Z.; writing-review and editing, H.L. and X.-a.Z.; supervision, X.-a.Z.; funding acquisition, X.-a.Z. All authors have read and agreed to the published version of the manuscript.

Funding: This work was mainly supported by NSERC through a Discovery Grant (\# 489075). We are grateful to the University of Toronto Scarborough, Canada Foundation for Innovation, and Ontario Research Fund awarded to X.-a.Z.

Acknowledgments: We thank Tony Adamo for technical support at the UTSC TRACES centre.

Conflicts of Interest: The authors declare no conflict of interest.

\section{References}

1. Magnetic Resonance Angiography; Carr, J.C.; Carroll, T.J. (Eds.) Springer: New York, NY, USA, 2012. [CrossRef]

2. Saeed, M.; Wendland, M.F.; Higgins, C.B. Blood Pool MR Contrast Agents for Cardiovascular Imaging. J. Magn. Reson. Imaging 2000, 12, 890-898. [CrossRef]

3. Lauffer, R.B.; Parmelee, D.J.; Ouellet, H.S.; Dolan, R.P.; Sajiki, H.; Scott, D.M.; Bernard, P.J.; Buchanan, E.M.; Ong, K.Y.; Tyeklár, Z.; et al. MS-325: A Small-Molecule Vascular Imaging Agent for Magnetic Resonance Imaging. Acad. Radiol. 1996, 3, S356-S358. [CrossRef]

4. Caravan, P.; Cloutier, N.J.; Greenfield, M.T.; McDermid, S.A.; Dunham, S.U.; Bulte, J.W.M.; Amedio, J.C.; Looby, R.J.; Supkowski, R.M.; Horrocks, W.; et al. The Interaction of MS-325 with Human Serum Albumin and Its Effect on Proton Relaxation Rates. J. Am. Chem. Soc. 2002, 124, 3152-3162. [CrossRef] [PubMed]

5. Morcos, S.K. Extracellular Gadolinium Contrast Agents: Differences in Stability. Eur. J. Radiol. 2008, 66, 175-179. [CrossRef] [PubMed]

6. McDonald, R.J.; McDonald, J.S.; Kallmes, D.F.; Jentoft, M.E.; Murray, D.L.; Thielen, K.R.; Williamson, E.E.; Eckel, L.J. Intracranial Gadolinium Deposition after Contrast-Enhanced MR Imaging. Radiology 2015, 275, 772-782. [CrossRef] [PubMed]

7. Kanda, T.; Fukusato, T.; Matsuda, M.; Toyoda, K.; Oba, H.; Kotoku, J.; Haruyama, T.; Kitajima, K.; Furui, S. Gadolinium-Based Contrast Agent Accumulates in the Brain Even in Subjects without Severe Renal Dysfunction: Evaluation of Autopsy Brain Specimens with Inductively Coupled Plasma Mass Spectroscopy. Radiology 2015, 276, 228-232. [CrossRef] [PubMed]

8. Cheng, W.; Haedicke, I.E.; Nofiele, J.; Martinez, F.; Beera, K.; Scholl, T.J.; Cheng, H.-L.M.; Zhang, X.-A. Complementary Strategies for Developing Gd-Free High-Field $T_{1}$ MRI Contrast Agents Based on Mn III Porphyrins. J. Med. Chem. 2014, 57, 516-520. [CrossRef] [PubMed]

9. Haedicke, I.E.; Li, T.; Zhu, Y.L.K.; Martinez, F.; Hamilton, A.M.; Murrell, D.H.; Nofiele, J.T.; Cheng, H.-L.M.; Scholl, T.J.; Foster, P.J.; et al. An Enzyme-Activatable and Cell-Permeable Mn III-Porphyrin as a Highly Efficient T 1 MRI Contrast Agent for Cell Labeling. Chem. Sci. 2016, 7, 4308-4317. [CrossRef] [PubMed]

10. Nofiele, J.T.; Haedicke, I.E.; Zhu, Y.L.K.; Zhang, X.-A.; Cheng, H.-L.M. Gadolinium-Free Extracellular MR Contrast Agent for Tumor Imaging: Gd-Free Contrast Agent for Tumor MRI. J. Magn. Reson. Imaging 2015, 41, 397-403. [CrossRef] [PubMed]

11. Zhang, X.-A.; Lovejoy, K.S.; Jasanoff, A.; Lippard, S.J. Water-Soluble Porphyrins as a Dual-Function Molecular Imaging Platform for MRI and Fluorescence Zinc Sensing. Proc. Natl. Acad. Sci. USA 2007, 104, 10780-10785. [CrossRef] [PubMed] 
12. Liu, H.; Zhang, X.-A. Manganese-Based Magnetic Resonance Imaging Contrast Agents. In Encyclopedia of Inorganic and Bioinorganic Chemistry; Scott, R.A., Ed.; John Wiley \& Sons, Ltd.: Chichester, UK, 2018; pp. 1-16. [CrossRef]

13. Raman, F.S.; Nacif, M.S.; Cater, G.; Gai, N.; Jones, J.; Li, D.; Sibley, C.T.; Liu, S.; Bluemke, D.A. 3.0-T Whole-Heart Coronary Magnetic Resonance Angiography: Comparison of Gadobenate Dimeglumine and Gadofosveset Trisodium. Int. J. Cardiovasc. Imaging 2013, 29, 1085-1094. [CrossRef] [PubMed]

14. Cheng, W.; Ganesh, T.; Martinez, F.; Lam, J.; Yoon, H.; Macgregor, R.B.; Scholl, T.J.; Cheng, H.-L.M.; Zhang, X.-A. Binding of a Dimeric Manganese Porphyrin to Serum Albumin: Towards a Gadolinium-Free Blood-Pool T 1 MRI Contrast Agent. J. Biol. Inorg. Chem. 2014, 19, 229-235. [CrossRef] [PubMed]

15. Cheng, H.-L.M.; Haedicke, I.E.; Cheng, W.; Tchouala Nofiele, J.; Zhang, X.-A. Gadolinium-Free $T_{1}$ Contrast Agents for MRI: Tunable Pharmacokinetics of a New Class of Manganese Porphyrins: Tunable Gadolinium-Free $T_{1}$ Contrast Agents. J. Magn. Reson. Imaging 2014, 40, 1474-1480. [CrossRef] [PubMed]

16. Nofiele, J.T.; Cheng, W.; Haedicke, I.E.; Ganesh, T.; Zhang, X.-A.; Cheng, H.-L.M. Ultrashort Echo Time Magnetic Resonance Imaging of the Lung Using a High-Relaxivity $\mathrm{T}_{1}$ Blood-Pool Contrast Agent. Mol. Imaging 2014, 13, 7290.2014.00027. [CrossRef]

17. Lindsey, J.S.; Schreiman, I.C.; Hsu, H.C.; Kearney, P.C.; Marguerettaz, A.M. Rothemund and Adler-Longo Reactions Revisited: Synthesis of Tetraphenylporphyrins under Equilibrium Conditions. J. Org. Chem. 1987, 52, 827-836. [CrossRef]

18. Punna, S.; Diaz, D.D.; Finn, M.G. Palladium-Catalyzed Homocoupling of Arylboronic Acids and Esters Using Fluoride in Aqueous Solvents. Synlett 2004, 13, 2351-2354. [CrossRef]

19. Boucher, L.J. Manganese Porphyrin Complexes. Coord. Chem. Rev. 1972, 7, 289-329. [CrossRef]

(C) 2020 by the authors. Licensee MDPI, Basel, Switzerland. This article is an open access article distributed under the terms and conditions of the Creative Commons Attribution (CC BY) license (http://creativecommons.org/licenses/by/4.0/). 